The research schemes covered a wide range of problems in biology and public health, engineering, essential and vegetable oils, fuel, leather and food technology, metallurgy, pharmaceuticals and drugs, and physies, while a research school in earthquake engineering was established at Roorkee University.

It is impossible here to do more than refer very briefly to a few features of the work of some of the National Laboratories and Institutes to illustrate the range of the Council's activities. The National Physical Laboratory, New Delhi, was responsible for theoretical investigations on the conduction of heat in solids, and an evaluation of the convolution integral with particular reference to its application in heat conduction when the excitation function is an arbitrarily plotted function of time. Broadcast transmission of time signals over a standard carrier of $10 \mathrm{Mc} / \mathrm{s}$. continued for $5 \mathrm{hr}$. daily on an experimental basis, and also investigations on the determination of the minimum amount of costly materials which suffices for the correct measurement of their melting points which are fixed points of temperature, and the internal energies of tantalum, platinum and titanium have been calculated. The National Chemical Laboratory, Poona, has developed a new complexing eluant, sodium triphosphate, particularly useful in preparing pure samaria from a 30 per cent samarium concentrate, and has also developed a general theory of super-exchange interaction mechanism and satisfactory processes for production of theophylline, sodium warfarin, $N$-methyltaurine and methylamine and for recovering quinine and quinidine from cinchona febrifuge, as well as a new route to naturally occurring anthraquinone carbinols using diborane.
The Central Drug Research Institute, Lucknow, has found, in indigenous medicinal plants screened for pharmacological activity, a good cardiovascular drug in ruvoside, from Thevetia neriifolia (Kaner) and a drug with musculotrophic properties in Daemia extensor (Utranjutaka), and obtained evidence of amœbicidal activity in deoxyhexahydroquinine, while immunochemical work on Vibrio cholerae has shown that neutral and acid polysaccharide fractions possess high serological activity. The Central Electroclinical Research Institute, Karaikudi, has developed a new technique for preparing $2: 4$-diaminophenol by electrolytic reduction of $m$-dinitrobenzene, and has used a rotating-cathode technique in the preparation of benzidine and substituted benzidines, while a new cathodic technique has been developed for the study of cathode protection based on the use of the Hull cell and a polarographic technique used for the determination of cystine. The Regional Research Laboratory, Hyderabad, has prepared short-, mediumand long-oil varnishes from maleic and modified phenolic resins, using dehydrated castor oil, bodied dehydrated castor oil and linseed stand oil, and established optimum conditions for the preparation of terpeneol from carene, 8-hydroxyquinoline from $o$-aminophenol, phenylacetic acid from benzyl chloride and phenylacetamide from benzyl cyanide.

The Indian Institute for Biochemistry and Experimental Medicine, Calcutta, has gained a clearer understanding of the biological activity of human chorionic gonadotrophin which accelerates the transformation of germ cells in the male toad, and has also obtained a comprehensive idea of the pattern of metabolism supporting growth and activity in Leishmania donovani.

\title{
RADIO RESEARCH 1960
}

\begin{abstract}
$\mathrm{T}$ HE Radio Research Board of the Department of Scientific and Industrial Research was established in 1920, and has in the intervening forty years continuously advised the Department on its programme of research in the radio field. For many years the work was centred on the National Physical Laboratory at Teddington, although facilities for field experiments were long ago made available in the grounds of the Admiralty Compass Observatory, at Ditton Park, near Slough. Dr. R. L. Smith-Rose has been associated with this research programme from its inception, and in 1947 he was appointed as the first director of radio research of the Department of Scientific and Industrial Research. Following this appointment, the Radio Research Station at Slough, with its new laboratories erected in 1956 , became the centre for the radio research work of the Department and independent of the National Physical Laboratory.

The report of the Radio Research Board for 1960, published recently*, records that Dr. R. L. SmithRose retired from his post of director of radio research on September 30, when he was succeeded by Mr. J. A. Ratcliffe from the Cavendish Laboratory, University of Cambridge.

* Department of Scientific and Industrial Research. Radio Research 1960: The Report of the Radio Research Board and the Report of the Director of Radio Research. Pp. iv $+23+4$ plates (London: H.M.S.O., 1961.) 2s. $6 d$. net.
\end{abstract}

During the year, the work of the Station was re-oriented so as to apply about 50 per cent of its effort to some space research problems, which are now being actively investigated. To assist in this work, a major development during the year under review was the installation of a 'Minitrack' equipment for tracking artificial satellites of the Earth, and for communication with, and reception of, telemetry signals from such satellites. The equipment has been provided on loan by the National Aeronautics and Space Administration (N.A.S.A.) of the United States, and is operated by staff of the Station. Data obtained from it are available for use by both organiza. tions.

Predictions, on an increased scale, have continued to be issued during the year, giving the positions of all satellites of interest to observers in the United Kingdom. Signals have been received from a number of satellites at Winkfield, near Slough, and at the Radio Research sub-station at Singapore; and measurements have been made of signal strength, Doppler frequency-shift, and Faraday fading effects. The results are of particular interest in work on the ionosphere both in temperate and equatorial regions.

For many years the Radio Research Station has been very actively engaged in exploring the ionosphere by radio waves sent up from the surface of the Earth. During the past year, collaboration with the corre- 
sponding Canadian and United States laboratories has continued in the development of a technique to use satellites for sounding the ionosphere from above'top-side sounding' as it is called. The station at Port Stanley in the Falkland Islands, one of the Department's ionospheric observatories for many years past, will also be engaged in receiving signals from these and other satellites.

The ionospheric forecasting service provided by the Radio Research Station has always been used by civilian and defence organizations in the planning of their long-distance high-frequency communication circuits. With the knowledge of ionospheric behaviour that has been accumulated at the Station, consideration is now being given to the production of a reference book containing details of all ionospheric conditions likely to be encountered throughout the world. A single figure or index derived from observations at a few ionospheric sounding stations would be used as a guide to find out the conditions prevailing at any time and place.

During the period under review, the analysis of the atmospheric radio noise data obtained during the International Geophysical Year has been continued. The main experimental work during the year has been the recording of single atmospherics from storms at known short distances; and the evaluation of the peak power and total radiated energy from lightning discharges. At frequencies greater than $30 \mathrm{Mc} / \mathrm{s}$., interference from atmospheric noise is not of major importance for ground receiving atations. But the need to find a 'quiet' site for the Station's projected radio telescope has indicated that manmade noise, due to electrical machinery and the like, may cause serious disturbance. Accordingly, measurements are being made in the higher radio frequency bands to determine more precisely the levels of such man-made noise.

There are still many problems awaiting solution in connexion with the transmission of radio waves over both long and short distances through the troposphere. A detailed knowledge of the propagation conditions for very-high and ultra-high frequencies is of particular importance in connexion with the future development and planning of broadcasting, including television, services throughout the world. Staff of the Radio Research Station collaborate with the Post Office and the British Broadcasting Corporation in experimental investigations in Britain. But, on a wider scale, they also participate in the work of the International Radio Consultative Committee (C.C.I.R.), concerning the planning, over a wide geographical area, of transmitters using the same or adjacent frequency channels, in such a way as to avoid mutual interference.

Closely associated with this work is the direct experimental study of the refractive index structure of the troposphere by two techniques: one of these uses an airborne micro-wave refractometer for direct measurements at various heights; the other comprises radar sounding of the tropospheric layers at vertical incidence. Preliminary investigations have been made by both methods, and improved equipment has been under development during the year.

While the work on the electrical properties of components and materials, such as transistors and ferrites, has been terminated during the year, the past experience gained in this type of investigation is proving valuable in the development of techniques and equipment used in other parts of the research programme. Apart from this, however, all aspects of the programme demand facilities for the accurate measurement of various parameters; it is a continuing policy of the Station to conduct research on the appropriate measurement techniques.

As in the case of former published reports, that for 1960 contains three appendixes. The first gives the references to 36 scientific papers published by the staff during the year. The second is a list of staff of the Radio Research Organization on January 1, 1961 ; while the third gives the terms of reference and constitution of committees of the Radio Research Board. These committees provide the expert advice on which the Board frames its recommendations for the present and future programmes of research.

\title{
BIOLOGICAL CONTROL OF CONCEPTION*
}

\author{
By DR. A. S. PARKES, C.B.E., F.R.S.
}

National Institute for Medical Research, Mill Hill, London, N.W.7

T HE Oliver Bird Lectures and the Oliver Bird Prize were instituted with the idea of reviewing and stimulating work bearing on the control of conception in man. Such review and stimulation were badly needed. In many countries of the world, population is increasing at an unprecedented and accelerating rate. The increase is not due to any sudden increase in human fertility; it is due to the work of medical science in decreasing mortality and increasing the expectation of life at birth in many parts of the world where the birth-rate is still high. Total world population is now around 3,000 million, just about double the number thought to have existed at the beginning of this century. Population growth cannot go on indefinitely at this rate. Something will happen to stop it, and the human race must

* Substance of the fifth Oliver Bird Lecture delivered on June 20. decide whether that something is to be pleasant or unpleasant.

Different countries are contributing in very different degrees to this population explosion. In the United Kingdom the small natural increase in population now occurring is not in itself causing any new problems. But the practical, æesthetic and eugenic requirements of the individual in relation to the control of conception are far from satisfied. In countries faced with a crippling increase in population it is vitally necessary that a simple and effective method of controlling fertility shall be evolved. It is not surprising, therefore, that intensive, though belated, work is now in progress with the view of applying existing knowledge of the physiology and biochemistry of the processes leading to conception to provide better methods of preventing it, and to 